\title{
IMPLEMENTASI MIKROKONTROLER PADA BROODER LISTRIK UNTUK KANDANG BROILER TIPE CLOSED HOUSE
}

\author{
Microcontroller Implementation on Electric Brooder for Closed Type Poultry House
}

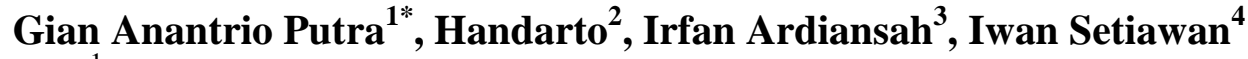 \\ ${ }^{1}$ Prodi Teknik Biosistem, Institut Teknologi Sumatera, Lampung \\ ${ }^{2}$ Prodi Teknik Pertanian dan Biosistem, Universitas Padjadjaran, Jawa Barat \\ ${ }^{3}$ Prodi Teknologi Industri Pertanian, Universitas Padjadjaran, Jawa Barat \\ ${ }^{4}$ Fakultas Peternakan, Universitas Padjadjaran, Jawa Barat \\ Email korespondensi: gian.putra@tb.itera.ac.id
}

\begin{abstract}
ABSTRAK
Broiler merupakan unggas yang membutuhkan suhu udara yang konstan untuk tumbuh. Perubahan suhu yang ekstrim menyebabkan broiler menderita stres, lambat tumbuh, dan bahkan mati. Brooder diperlukan untuk memberikan panas agar suhu kandang tidak berada di bawah nilai minimum suhu optimal bagi pertumbuhan broiler. Penelitian ini bertujuan modifikasi brooder listrik konvensional agar dapat menjaga suhu udara kandang broiler pada kisaran optimum secara otomatis dan menganalisis hasil implementasi microcontroller pada brooder listrik hasil modifikasi tersebut. Metode yang digunakan adalah metode deskripsi analitik dan rekayasa. Uji verifikasi dan uji validasi dilakukan terhadap brooder dalam empat tingkat penyalaan pemanas: $500 \mathrm{~W}$, $1.000 \mathrm{~W}, 1.500 \mathrm{~W}$ dan $2.000 \mathrm{~W}$. Hasilnya adalah sistem pengendali yang membuat brooder listrik dapat dioperasikan secara otomatis dengan mudah serta secara sekaligus merekam data suhu udara secara real-time.
\end{abstract}

Keywords: DOC, mikrokontroler, otomasi, sistem kontrol, suhu optimum

\begin{abstract}
Broilers are aves that require a constant air temperature to grow. Extreme temperature changes cause the broiler suffering from stress, slow growing, and even death. Brooder provides heat so the air temperature of poultry house is not below the minimum optimum air temperature for broiler growth. The objectives of this research are to modify the conventional electric brooder which aims to keep the poultry house's air temperature on its optimum range automatically and to observe application of microcontroller on modified electric brooder. This research use analitical descriptive and experimental methods. Verification and validation tests are applied for four levels of brooding: $500 \mathrm{~W}, 1,000 \mathrm{~W}, 1,500 \mathrm{~W}$ and 2,000 W. The results showed that the control system makes the electric brooder can be operated easily and automatically, and also can record the air temperature data in real-time.
\end{abstract}

Keywords: automation, control system, DOC, microcontroller, optimum temperature

\section{PENDAHULUAN}

Brooder merupakan alat bantu yang diperlukan terutama pada kandang indukan untuk memberikan kehangatan kepada DOC saat pemeliharaan anak broiler umur 1 hari sampai berumur 2-3 minggu (Haris, 2007). Menurut Unandar (2009), minggu pertama bagi broiler 
adalah sangat penting sekali. Oleh karena itu, harus ada perhatian yang ekstra lebih pada saat umur itu. Suhu lingkungan menjadi sangat penting, karena pada akhir minggu pertama bobot harus mencapai 4 (empat) kali lipat dari bobot awal. Pada broiler umur 4 minggu, pertumbuhan bulu masih sangat sedikit, akan tetapi pertumbuhan ototnya sudah demikian pesat. Akibatnya, jika fungsi dan keberadaan brooder tidak optimal, sudah pasti akan menyebabkan terganggunya pertumbuhan dan perkembangan, termasuk dalam hal pertumbuhan organorgan penting dalam kehidupannya antara lain sistem pencernaan dan sistem kekebalan tubuhnya.

Umumnya mekanisme pengaturan brooder di peternakan broiler di tanah air, termasuk juga mekanisme pengaturan brooder yang dilakukan di kandang broiler tipe closed house milik Fakultas Peternakan Universitas Padjadjaran, masih dilakukan secara manual berdasarkan pengalaman dari anak kandang. Hal ini dilakukan dengan mengamati beberapa parameter tingkah laku yang ditunjukkan oleh DOC. Jika DOC menunjukkan perilaku yang menunjukkan suhu kandang rendah, maka brooder akan diatur menjadi lebih tinggi tingkat pemanasannya daripada sebelumnya, dan akan diatur menjadi lebih rendah jika dirasa suhu kandang melebihi batas optimal dengan cara memperbesar atau memperkecil bukaan bahan bakar gas dari tabung menuju brooder.

Tujuan penelitian ini adalah memodifikasi brooder listrik manual menjadi brooder listrik otomatis, sehingga brooder tersebut mampu menjaga suhu udara kandang optimum setiap saat.

\section{METODE PENELITIAN}

Penelitian dilaksanakan di Laboratorium Komputer, Jurusan Teknik Pertanian dan Biosistem, Universitas Padjadjaran, Jatinangor. Penelitian pendahuluan yang meliputi pengukuran beberapa tipe brooder dilakukan di Kandang Broiler Tipe Closed House, Fakultas Peternakan, Universitas Padjadjaran, Jatinangor.

Metode penelitian yang akan digunakan dalam penelitian ini adalah analitik deskriptif dan rekayasa. Metode analitik deskriptif meliputi pengukuran dan observasi. Metode rekayasa meliputi perakitan brooder listrik, serta perancangan sistem otomasinya yang meliputi pemrograman mikrokontroler serta pembuatan hardware itu sendiri.

Penelitian ini seperti dijabarkan pada Gambar 1 akan dilakukan dengan 
beberapa tahapan, yaitu penelitian Setelah kedua hal itu selesai dilaksanakan, pendahuluan yang meliputi observasi dan maka akan dilakukan evaluasi yang terdiri analisis data, kemudian dilanjutkan dari uji verifikasi dan uji validasi. dengan perakitan dan pemrograman.

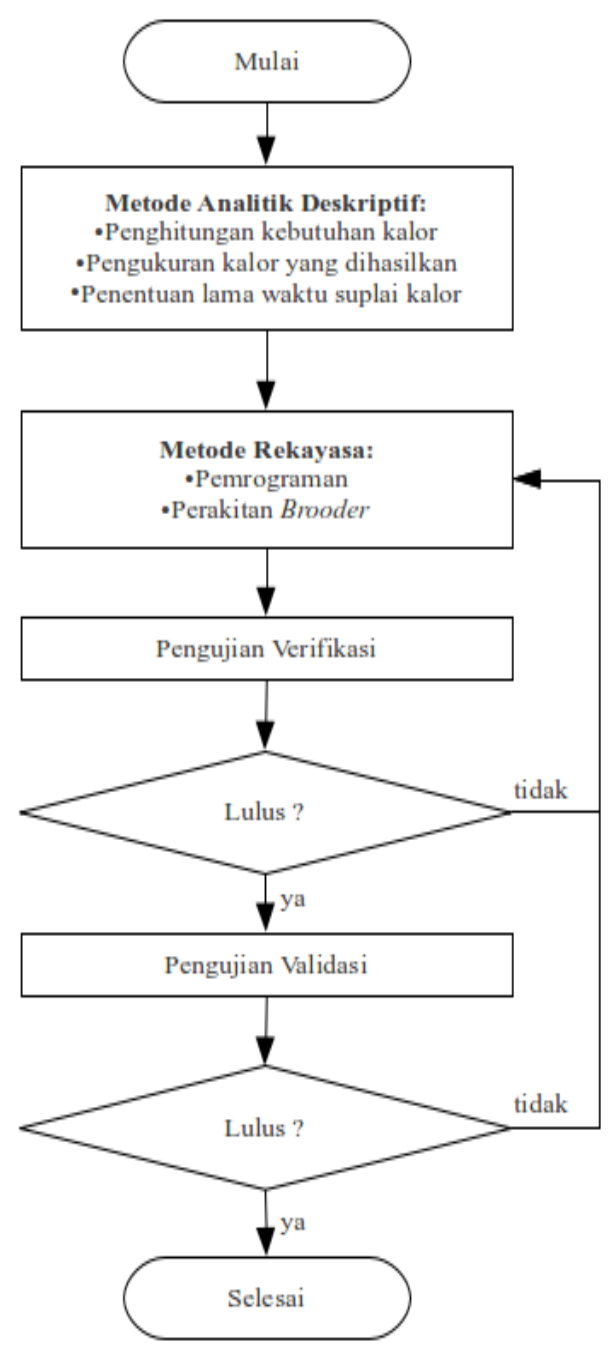

Gambar 1. Diagram alir implementasi Mikrokontroler pada Brooder Listrik

Untuk program otomasi, diagram anak kandang cukup memasukkan usia alirnya dapat dilihat pada Gambar 2. Pada DOC saja, dan kemudian brooder akan program yang akan dibuat, peternak atau bekerja secara otomatis. 


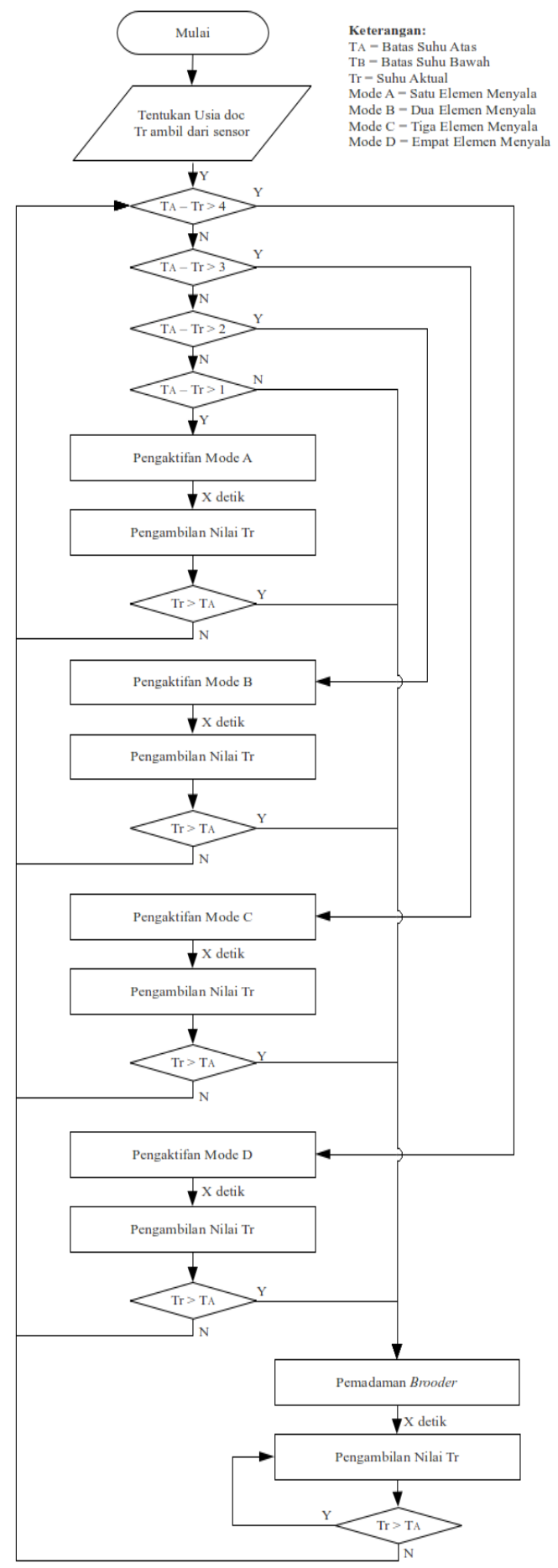

Gambar 2. Diagram alir program otomasi brooder

Uji verifikasi dilakukan untuk memastikan apakah sistem sudah dibuat dengan benar. Maka dilakukan pengujian pada program, apakah program sudah ditulis sesuai dengan kaidah yang berlaku dan dapat berjalan. Uji validasi dilakukan untuk menguji alat hasil penelitian, apakah sistem yang dibuat sudah benar. Apakah purwarupa brooder otomatis yang dibuat, dapat bekerja dengan baik sesuai dengan instruksi yang sudah ditanamkan kedalamnya. Parameter yang akan diuji antara lain: tingkat akurasi dan sensitivitas sensor suhu, mekanisme inisiasi penyalaan brooder, mekanisme inisiasi pemadaman brooder, mekanisme inisiasi penyalaan brooder pada masing-masing mode.

\section{HASIL DAN PEMBAHASAN}

Purwarupa brooder dibuat dalam skala 1:1, ukuran panjang dan lebar rangka adalah $20 \mathrm{~cm}$, tinggi rangka $70 \mathrm{~cm}$, dan ukuran luasan tudung brooder $60 \mathrm{~cm}$ x $60 \mathrm{~cm}$. Sumber panas adalah empat buah lilitan kawat nikelin, dengan masingmasing daya kawat nikelin tersebut sebesar 500 W. Terdapat sebuah kipas untuk melakukan konveksi paksa.

\section{Rangkaian instrumentasi kontrol} dan logger terpisah dengan brooder, disambungkan dengan kabel yang berfungsi untuk memberikan perintah aktivasi-deaktivasi relay pada bagian bawah brooder. 


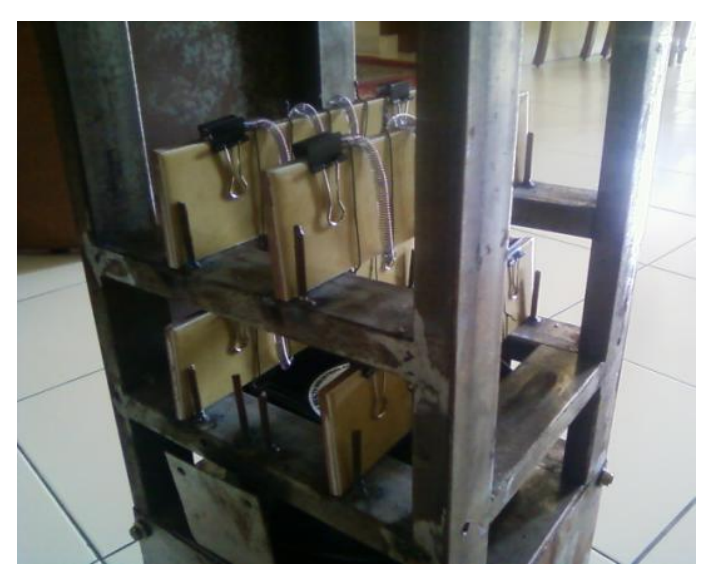

Gambar 3. Sumber panas purwarupa brooder

Uji verifikasi program dilakukan oleh IDE Arduino 1.0 yang dapat diunduh di laman web Arduino, verifikasi dilakukan dengan menggunakan fasilitas "verify" setelah menulis seluruh baris program yang dibuat. Setelah dilakukan uji verifikasi pada program, hasilnya adalah program tersebut memenuhi logika pemrograman yang berlaku.

Gambar 4. Aliran udara brooder

Untuk mengetahui kinerja secara umum masing-masing mode pada brooder ini, dilakukan penyalaan elemen satu persatu, dimulai dari penyalaan satu buah elemen pemanas saja, kemudian dilanjutkan dengan penyalaan satu elemen pemanas tambahan ketika suhu udah tidak mengalami kenaikan, dan begitu seterusnya sehingga keempat buah elemen pemanas menyala semuanya.
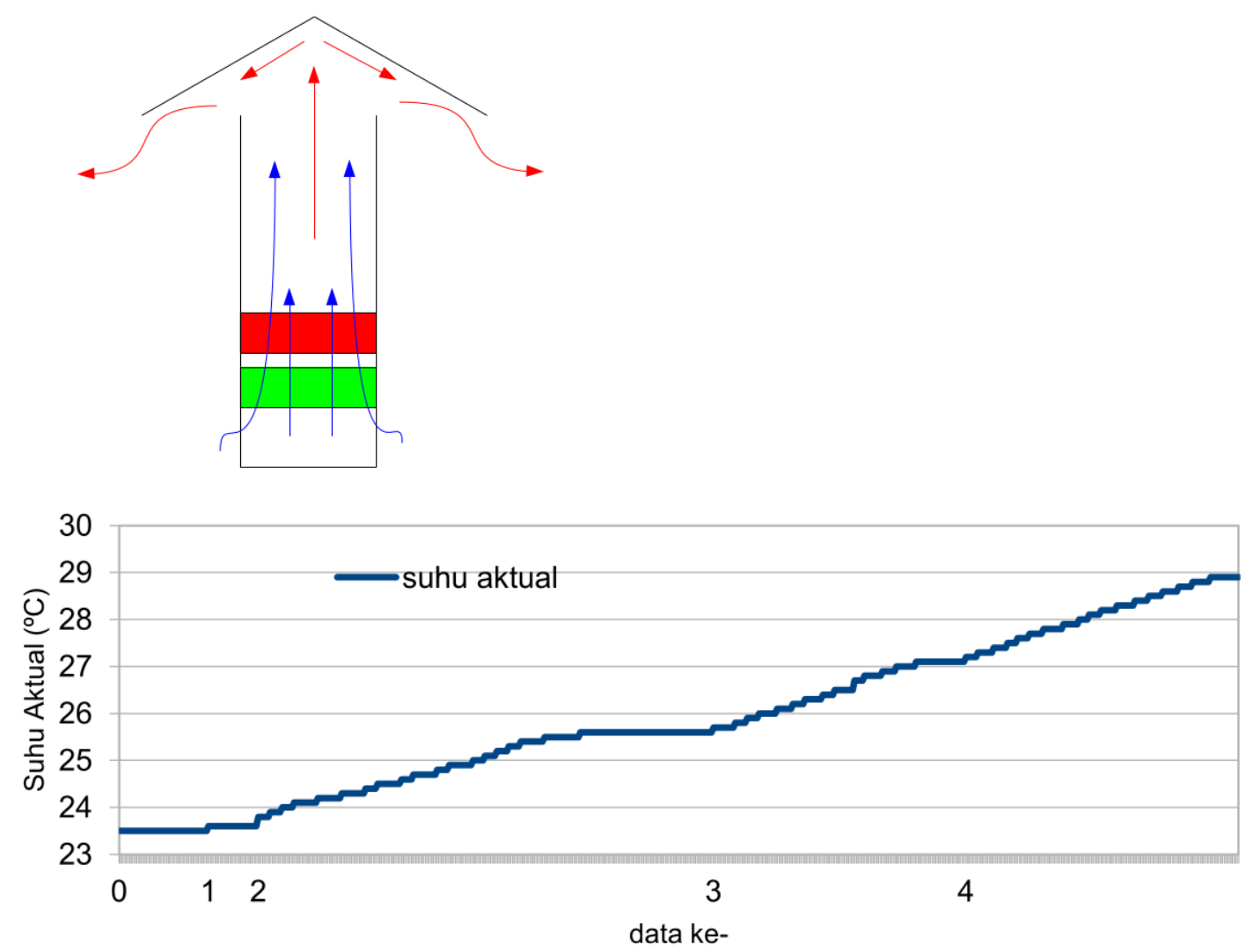

Gambar 5. Grafik pergerakan suhu naik 


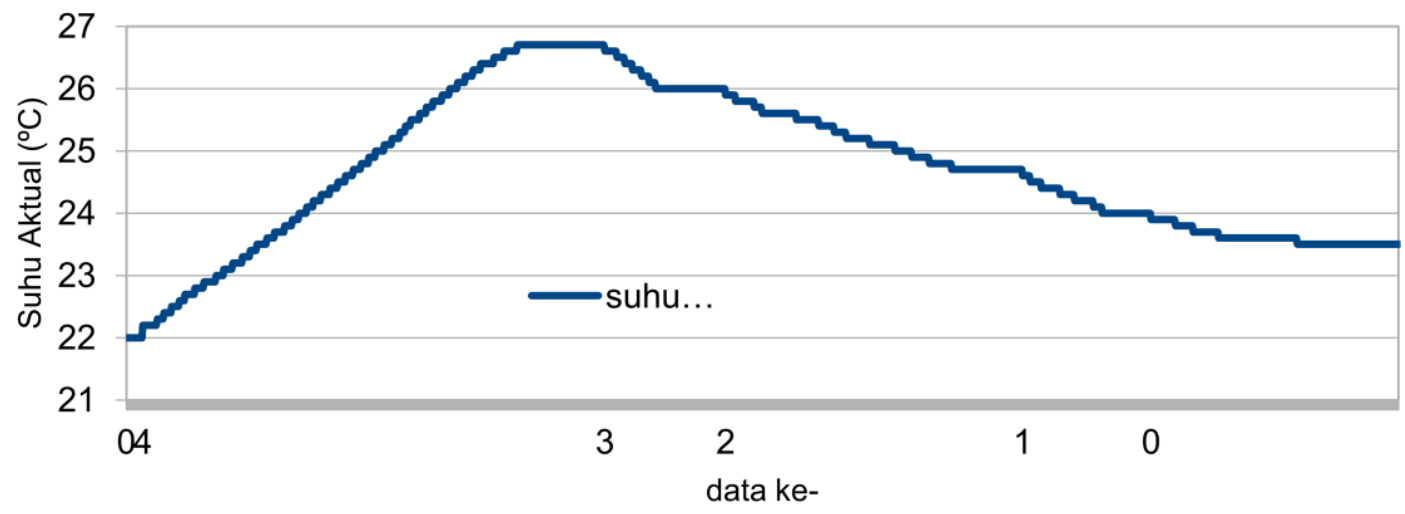

Gambar 6. Grafik pergerakan suhu turun

Hasilnya adalah ketika satu elemen pemanas dinyalakan, hanya akan memberikan kontribusi kenaikan suhu sebesar $0,1^{\circ} \mathrm{C}$, dua elemen sebesar $2,0^{\circ} \mathrm{C}$, tiga elemen sebesar $1,6{ }^{\circ} \mathrm{C}$, dan empat elemen sebesar $1,7{ }^{\circ} \mathrm{C}$. Dengan lama penyalaan secara berurutan selama 5 menit, 38 menit, 21 menit, dan 28 menit seperti dapat dilihat pada Gambar 5.

Kemudian dilakukan pengambilan data yang dimulai dengan penyalaan empat sumber panas secara langsung, dan kemudian dimatikan satu per satu hingga mencapai suhu ruang kembali. Seperti dapat dilihat pada Gambar 6, ketika keempat sumber panas dinyalakan, suhu bergerak naik dari suhu ruang $22{ }^{\circ} \mathrm{C}$ hingga $26,7{ }^{\circ} \mathrm{C}$ selama 1 jam. Kemudian ketika satu sumber panas dimatikan, suhu turun menjadi $26{ }^{\circ} \mathrm{C}$ selama 18 menit. Ketika satu sumber dimatikan lagi, suhu turun menjadi $24,7{ }^{\circ} \mathrm{C}$ selama 45 menit.
Setelah 17 menit, suhu udara konstan di 24,7 ${ }^{\circ} \mathrm{C}$ akhirnya brooder dimatikan secara penuh dan kembali mencapai suhu ruang sebesar $23,5^{\circ} \mathrm{C}$ setelah dimatikan selama 30 menit.

\section{KESIMPULAN}

Kesimpulan yang dapat diambil selama proses perancangan, pengujian dan pembahasan purwarupa brooder, adalah modifikasi brooder listrik konvensional menjadi brooder listrik otomatis telah dilakukan dengan mengganti sumber panas brooder dan mengaplikasikan mikrokontroler sebagai pengendalinya, sehingga brooder listrik dapat dioperasikan secara otomatis dengan mudah serta secara sekaligus merekam data suhu udara secara real-time. 


\section{SARAN}

Terdapat beberapa saran untuk memaksimalkan fungsi brooder otomatis ini, antara lain:

1. Melakukan penelitian tentang pengaruh panjang kabel terhadap sinyal analog yang dihantarkan sensor.

2. Menggunakan sensor sejenis lainnya yang dapat memberikan hasil pembacaan dengan lebih baik dan akurat.

3. Menambahkan jumlah sensor dengan kabel yang lebih panjang, agar sensor dapat mencapai beberapa titik di dalam kandang sekaligus.

\section{UCAPAN TERIMA KASIH}

Artikel ini merupakan bagian dari

Skripsi yang dilakukan oleh penulis.

\section{DAFTAR PUSTAKA}

Adiaty, S. (2010). Analisis Suhu dan Kelembaban Relatif Udara di Dalam Kandang Broiler Tipe Closed House. Skripsi. Fakultas Teknologi Industri Pertanian Universitas Padjadajaran Bandung. Jatinangor.

Ashari, M. (2009). Desain Pengatur Temperatur Ruangan untuk Pemeliharaan Anak Ayam Kampung Secara Otomatis dengan Menggunakan teknologi VHDL Berbasis CPLD. Seminar Nasional
Electrical, Informatics, and it's Education 2009 (pp. A2-60 - A265). Malang: Jurusan Teknik Elektro, Universitas Negeri Malang. Christofer, G., Sujaini, H., Irwansyah, M. A. (2015). Rancang Bangun Aplikasi Early Warning dengan Pemanfaatan Pengukuran Suhu Ruangan Berbasiskan Arduino Mega 2560. Jurnal Sistem dan Teknologi Informasi 3(3). 1-5. http://dx.doi.org/10.26418/justin.v3i 3.11474

Găşpăresc, G. (2013). Development of a low-cost System for Temperature Monitoring. $201336^{\text {th }}$ International Conference on Telecommunications and Signal Processing (TSP) Rome: IEEE.

http://dx.doi.org/10.1109/TSP.2013. 6613948

Nugroho, A. (2010). Mekatronika. Yogyakarta: Graha Ilmu.

Parsons, R. (1989). ASHRAE Handbook Fundamentals, I-P Edition.

Pratomo, T. B., dkk. (2013). Purwarupa Sistem Kendali Suhu dengan Pengendali PID pada Sistem Pemanas dalam Proses Refluks/Distilasi. Indonesian Journal of Electronics and Instrumentation Systems 3(1), 23 34.

https://doi.org/10.22146/ijeis.3836

Suherman, S., Andriyanto, I., Dwiyatno, S. (2015). Rancang Bangun Alat Ukur Temperatur Suhu Perangkat Server Menggunakan Sensor LM35 Berbasis SMS Gateway. Jurnal Pengembangan Riset dan Observasi Sistem Komputer 2(1), 42-63. http://e-

jurnal.lppmunsera.org/index.php/PR OSISKO/article/view/97

Suprijatna, E., U. Atmomarsono, R. Kartasudjana. 2005. Ilmu Dasar Ternak Unggas. Jakarta: Penebar Swadaya. 
Tyas, D. A., Sumiharto, R. (2013).

Purwarupa Sistem Kendali PID: Studi Kasus Kendali Suhu Ruang. Indonesian Journal of Electronics and Instrumentation Systems 3(1), 95104. https://doi.org/10.22146/ijeis.3875

Winoto, A. 2008. Mikrokontroller AVR Atmega8/32/16/8535 dan Pemrogramannya dengan Bahasa $C$ pada WinAVR. Bandung: Informatika.

Yani, A. 2007. Analisis dan Simulasi Distribusi Suhu Udara pada
Kandang Sapi Perah Menggunakan Computational Fluid Dynamics (CFD). Thesis Pascasarjana Institut Pertanian Bogor. Bogor.

Yuan, Ben-hua. (2012). Design of the Temperature Measurement System Based on Arduino Board. Journal of Anhui Agriculutrial Sciences 20120 (8). http://en.cnki.com.cn/Article_en/CJ FDTOTAL-AHNY201208212.htm

Zain, S. 2005. Teknik Penanganan Hasil Pertanian. Bandung: Pustaka Giratuna. 